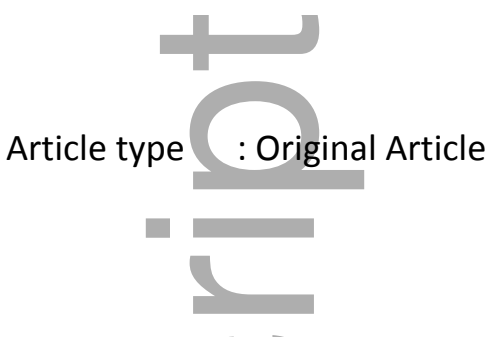

"I could do it in my own time and when I really needed it": perceptions of online pain coping skills training for people with knee osteoarthritis

Belinda J Lawford ${ }^{1}$ BMedSci, BHlthSci(Hons), PhD belinda.lawford@unimelb.edu.au

Rana S Hinman ${ }^{1}$ BPhysio(Hons), PhD ranash@unimelb.edu.au

Rachel K Nelligan ${ }^{1}$ BPhysio rachel.nelligan@unimelb.edu.au

Francis Keefe ${ }^{2}$, PhD keefe003@mc.duke.edu

Christine Rini ${ }^{3}$, PhD christine.rini@HackensackMeridian.org

Kim L Bennell ${ }^{1}$ BAppSci(Physio), PhD k.bennell@unimelb.edu.au

${ }^{1}$ Centre for Health, Exercise and Sports Medicine, Department of Physiotherapy, School of Health Sciences, The University of Melbourne. Victoria, Australia

${ }^{2}$ Duke Pain Prevention and Treatment Research Program, Duke Medical Centre, Durham, North Carolina, USA

${ }^{3}$ John Theurer Cancer Center, Department of Biomedical Research, Hackensack University Medical Center, Hackensack, NJ, Georgetown University School of Medicine, Washington, DC

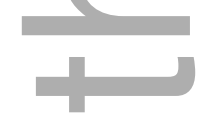

Correspondence and reprints: Dr Kim Bennell, Centre for Health Exercise and Sports Medicine, Department of Physiotherapy, School of Health Sciences, University of Melbourne, Parkville, Victoria, 3010, k.bennell@unimelb.edu.au

Key words: Osteoarthritis; pain coping skills training; online; qualitative; internet; knee

This is the author manuscript accepted for publication and has undergone full peer review but has not been through the copyediting, typesetting, pagination and proofreading process, which may lead to differences between this version and the Version of Record. Please cite this article as doi: $10.1002 /$ ACR.24093

This article is protected by copyright. All rights reserved 
Running Head: Experiences of online pain coping skills training

\section{Word Count: 3757}

Financial disclosures: The trial was funded by the Australian National Health and Medical Research Council (NHMRC) (program grant \#1091302). BJL is supported by a NHMRC Centre of Research Excellence (\#1079078). RSH is supported by a NHMRC Fellowship (\#1154217). KLB is supported by a NHMRC Fellowship (\#1058440). Development of the web-based PCST program was supported by the National Institute of Arthritis and Musculoskeletal and Skin Diseases, part of the United States National Institutes of Health, under Award Number R01 AR057346.

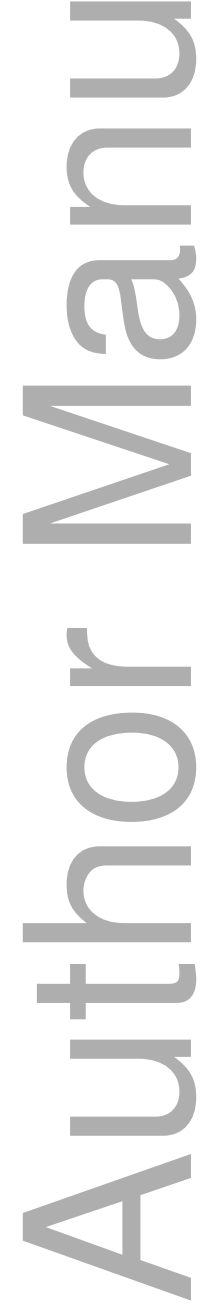




\section{Abstract}

Objective To qualitatively explore the perceptions and experiences of people with knee osteoarthritis (OA) who used an online automated pain coping skills training program (PCST).

Methods A descriptive qualitative study (based on interpretivist methodology) embedded within a randomised controlled trial. Individual semi-structured interviews were conducted with 12 people with knee OA who had participated in an 8-week automated online PCST program while also receiving exercise advice and support from a physiotherapist via Skype $^{\mathrm{TM}}$. Interviews in this study focused specifically on the online PCST program, rather than the physiotherapy component. Interviews were audio recorded, transcribed verbatim, and thematically analysed.

Results Five themes arose: 1) easy to understand and follow (clearly explained; presented well); 2) better able to cope with pain (controlling pain; helping relax; pacing self; incorporating skills into exercise program); 3) anonymity and flexibility (no judgement by clinician; work at own pace; accessibility); 4) not always relatable or engaging (some techniques not useful; Americanisation of the program; annoying character examples; time consuming and slow-paced); 5) support from clinician desirable (follow-up from a clinician would be beneficial; worked in tandem with physiotherapist-prescribed exercise; desire referral to the program by trusted source).

Conclusions People with knee OA had generally positive experiences using an online PCST program, suggesting that online PCST is a broadly acceptable and accessible way to help people with $\mathrm{OA}$ to manage their pain. User engagement may be enhanced by redesigning some aspects of the program, and provision of support from a clinician.

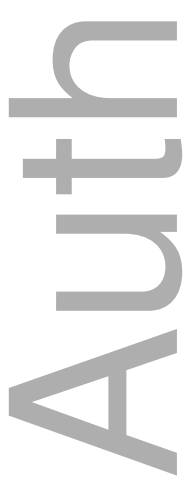




\section{Significance and Innovations}

- There is some evidence that online pain coping skills training (PCST) can improve pain, function, and psychological health in people with osteoarthritis, yet little is known about user perceptions of such programs.

- People with knee osteoarthritis who completed an automated online PCST program had generally positive experiences, suggesting that it is a broadly acceptable and accessible way to help people with OA to manage their pain.

- Findings suggest user engagement may be enhanced by redesigning some aspects of the program, such as making some aspects optional and ensuring the program is delivered in a context-specific way that is relevant to the local culture or patient group.

- Having support from a clinician was highlighted as being important and the program was perceived to work effectively in tandem with a physiotherapist-prescribed exercise program, suggesting that physiotherapists and other clinicians should consider incorporating online PCST programs as an adjunct to recommended core management approaches like exercise.

\section{Introduction}

Knee osteoarthritis (OA) is highly prevalent, affecting around $24 \%$ of the adult population [1] and incurring enormous direct and indirect healthcare costs [2]. All current clinical guidelines recommend education and advice, exercise, and, if appropriate, weight loss for management of OA $[3,4]$. Pain is the most common and debilitating symptom experienced by people with OA [5], and difficulty coping with pain has been associated with increased pain severity and greater emotional distress, muscle and joint tenderness, and pain-related disability, as well as poorer outcomes from treatment [6]. People with OA may also reduce their physical activity because they fear that movement will exacerbate their pain [7, 8]. As such, the development of effective and accessible psychological interventions that help people with OA cope with their pain is important $[9,10]$.

One such psychological intervention is pain coping skills training (PCST), a form of skills training informed by cognitive behavioural principles. PCST helps patients reconceptualise 
how thoughts, feelings, and behaviours influence pain and systematically trains them in skills such as relaxation, goal setting, and the use of positive coping thoughts to reduce pain catastrophizing [11]. Studies have shown that PCST leads to improvements in pain, physical function, and psychological distress in people with OA and rheumatoid arthritis [11]. Although PCST is generally delivered by a psychologist specialising in pain management, there is more recent evidence that a combined exercise and PCST intervention delivered by physiotherapists significantly improves pain and function in people with knee OA to a greater extent than either exercise or PCST alone [12].

Healthcare clinicians trained in the delivery of PCST, such as psychologists, may be difficult for some people with OA to access. For example, in Australia in 2016, there were only 23.8 and 14.8 psychologists per 100,000 population in remote and very remote areas, compared to 74.5 per 100,000 in major cities [13]. As such, delivering PCST remotely via the internet is one potential way to increase accessibility. An online self-guided PCST program was developed by our team in the USA to provide an accessible, low-cost option for people with OA who may be unable or unwilling to visit an appropriately trained clinician in-person [14]. One study investigated the efficacy and acceptability of that program in a 2-arm randomised controlled trial, finding that online PCST led to improvements in pain and self-efficacy for pain management amongst people with hip and/or knee OA [15]. Another more recent study investigated the effectiveness of delivering that same online PCST program before a home exercise program for people with hip OA, compared to the home exercise program alone [16]. Participants in the PCST group experienced improvements in pain coping as well as pain and function immediately after completing the program. However, although improvements in pain coping were sustained, there were no significant differences in pain and function between groups after the exercise program [16].

While there is emerging evidence supporting the efficacy of online PCST for people with OA, little is known about user perceptions of such programs, including whether they are perceived to be safe, effective, or useful. There is some evidence that patients with mental health issues [17] and people with bulimia [18] who have undergone internet-based psychological interventions (including cognitive behavioural therapy) valued the flexibility and accessibility, but expressed concerns about privacy, lack of face-to-face support, and the requirement for computer literacy. Cancer patients with bone pain who completed an online PCST program did not express similar concerns [19], reporting generally positive responses 
to the program's content, length, and function as well as the ability to use the program at home. To our knowledge, no previous studies have explored the perceptions people with OA have towards online PCST. Thus, the aim of this study was to qualitatively explore the perceptions and experiences of people with knee OA who participated in a randomised controlled trial (RCT) involving an online PCST program.

\section{Methods}

Design

A qualitative design based on interpretivist paradigm [20] was used to explore participants' experiences of our online PCST program. According to this paradigm, knowledge about a phenomenon is developed by gathering perceptions of participants who experience it [20]. This qualitative study was nested within the IMPACT randomised controlled trial [21] which evaluated the effectiveness of an intervention combining internet-delivered physiotherapistprescribed home exercise and online PCST. The Consolidated Criteria for Reporting Qualitative Research checklist was used to ensure complete and transparent reporting of this qualitative study [22].

\section{Participants}

A subset of participants from the intervention arm of the trial were invited via purposive sampling to participate in this nested qualitative study 3-6 months after completing the 3month intervention. This involved inviting a mix genders, a range of ages, and people from metropolitan and rural areas. Inclusion criteria for trial participants have been described in detail elsewhere [23] and briefly included being aged $\geq 50$ years, having persistent knee pain for more than three months and for most days of the past month, self-reporting a minimum average knee pain intensity walking score of 4 on an 11-point numerical rating scale and at least mild-moderate physical dysfunction (score $>20$ on the Western Ontario McMaster Universities (WOMAC) physical function subscale), and having access to a computer with internet connection. Participants were recruited Australia-wide via media campaigns and advertisements (e.g. in newspapers, university websites, and on Facebook and Twitter), and using our research volunteer database.

The final sample of 12 participants was dictated by the principle of theoretical saturation, where data were analysed in an ongoing manner after each interview and, when no new categories or themes emerged, no new participants were invited [24]. All participants 
provided written informed consent prior to participation and the institutional ethics committee approved the study.

\section{Intervention}

The intervention has been described in detail elsewhere [23]. Briefly, participants randomised to the intervention group received seven consultations with a physiotherapist delivered via Skype ${ }^{\mathrm{TM}}$, where they were prescribed an individualised home-based exercise program to be performed three times per week. Participants also simultaneously received login access to the PCST program, which was previously developed for research purposes and is guided by social cognitive theory and adult learning theories to ensure skill mastery [14]. Physiotherapy sessions generally occurred in week $2,3,4,6,8,10$, and 12 of the 3-month intervention, with participants asked to complete PCST modules in week 1-8, with a booster session at week 11 (involving an email encouraging participants to revisit the modules they found most useful). The PCST program involved eight 35-45-minute online modules to be completed at a rate of one session per week (described in Table 1). The first module provided an overview of the program, a therapeutic rationale involving a simplified version of gate control theory, and an introduction to progressive muscle relaxation as the first pain coping skill. The second to seventh modules taught: i) brief relaxation practices ("mini-practices"); ii) activity-rest cycling; iii) pleasant activity scheduling; iv) cognitive restructuring (developing "coping thoughts"); v) pleasant imagery, and; vi) problem solving. The final module taught strategies to enhance long-term use of pain coping skills.

Participants were led through the program by a female virtual coach who provided verbal descriptions and instructions of each pain coping skill, walked users through interactive exercises that allowed them to try a skill and review their experience with it, and followed up with feedback and encouragement to practice the skills. Instruction was mainly provided in audio format, with important points emphasised with onscreen text or graphics. Modules began with a review of the previous weeks' skill, including a review of the number of practice sessions the participant completed between modules. If participants had trouble completing practice sessions, the program gave prompts to help them identify why they did not practice, problem solve obstacles and challenges to practice, and develop solutions so they could improve next time. The new skill for that module was then introduced, after which participants were given a chance to practice using it and asked to evaluate their experience by, for example, rating how relaxed or calm they felt afterwards. At times throughout 
modules, characters modelled after OA patients appeared and spoke about their own experience using the skill, how it helped their pain, and how they dealt with challenges of applying the skill. At the end of the session, participants were asked to select practice goals for using their new skills in the coming week. Participants were able to go back to review previously-completed modules at any time.

The PCST program also included three optional modules to assist practice and enhance engagement: i) a module to help participants self-monitor their progress by setting goals, recording number of practice sessions completed, rating self-efficacy, and managing automated email reminders to practice; ii) a module that allowed participants to read about other people's experiences using the pain coping skills and write about their own experiences, and; iii) a module that provided participants with information about the program and actions to take in a medical or mental health emergency. The home page of the program also displayed reminders and badges that could be earnt by completing practice sessions and tasks.

Prior to starting the intervention, participants were mailed an instructional manual and workbook which included information on each session, as well as password access to the program. Participants also received monthly email reminders from the trial coordinator during the 6-months following the intervention to encourage them to continue their exercises and practice their pain coping skills. Physiotherapists were asked to encourage participants to complete the pain coping skills modules.

\section{Interviews}

Individual semi-structured interviews were conducted over the telephone by RKN, the coordinator of the IMPACT trial, who had phone screened and enrolled all trial participants and who is also a physiotherapist. The interview guide is displayed in Table 2. Interviews were audio recorded and transcribed verbatim by an external transcription service. Pseudonyms were assigned to each participant for confidentiality. Data were de-identified and stored in digital format on a password-protected university server.

\section{Data analysis}

Data analysis was based on a thematic approach [25]. Transcripts were read through by RKN soon after transcription to check for accuracy. BJL, a researcher trained and experienced in qualitative research methods, performed coding of transcripts. This involved reading through 
each transcript in detail and identifying topics and initial patterns of emerging ideas. Once each transcript had been coded, similar topics or ideas were grouped into categories, before being organised into broader themes and sub-themes. RKN, who performed all interviews, reviewed initial drafts of developing codes and themes to ensure that they reflected interview data. Final themes were reviewed and deliberated by all members of the analysis team (BJL, RKN, RSH, KLB). Disagreements were resolved through discussion until consensus was reached.

\section{Results}

Participants

Table 3 describes the twelve participants who were interviewed. The majority were female (58\%), living in metropolitan areas of Australia (58\%), had graduated from university/polytechnic or had postgraduate qualifications $(58 \%)$, and half were employed either full- or part-time (50\%).

\section{Themes}

Five themes arose (Table 4): i) easy to understand and follow; ii) better able to cope with pain; iii) anonymity and flexibility; iv) not always relatable or engaging, and; v) support from clinician desirable.

The first theme was: "easy to understand and follow". Participants found that the concepts and techniques presented in the PCST program were clearly explained in simple language that was easy to understand: "it made sense, you know I must say the whole program was very good in explaining the whys and [what] fors" Bob (Table 3 and 4). Participants also believed that the program was presented well by the main female virtual coach, in that it was not too "clinical" and that her voice was "calming" and "clear".

The second theme was: "better able to cope with pain". Most participants believed that the pain coping techniques that they learned helped them better control their pain and that they no longer felt overwhelmed by it. Participants had different perceptions about which techniques were most useful for them. Many found that the relaxation techniques (progressive relaxation and mini relaxation practices) helped them alleviate muscle tension and reduce stress. Participants valued the activity-pacing technique, finding that it helped them avoid flares in pain and break activities into smaller more manageable segments. The 
pain coping skills also helped participants control any pain experienced during the exercise program that was prescribed by the physiotherapists in the overarching IMPACT trial.

The third theme was: "anonymity and flexibility". One perceived advantage of the program being online was that it provided anonymity, in that participants felt that they were not being judged by a "smart" clinician. For example, participants felt more comfortable being able to go back into previous modules to clarify or review concepts themselves without feeling embarrassed by having to ask a clinician to do so in-person: "if I didn't understand something I could just replay it without feeling like I was a ditz" Alice (Table 3 and 4). The flexibility of the program was also an advantage, where participants found that they could progress at their own pace and at a time and place (e.g. home, work) that was convenient to them: "I liked the fact that I could do it in my own time when I was ready to do it and when I really needed it. I didn't have to worry about going somewhere having appointments." Sandra (Table 3 and 4).

The fourth theme was: "not always relatable or engaging". Many participants found that some of the techniques were not useful or applicable to them, in that they were "not finding the benefit" or that they "don't really think it added much value". However, there was no clear consensus on which techniques were the least helpful, and each participant had different preferences: "there are other strategies that might be appropriate for other people...I struggled with some of the techniques that they were trying to convince me to do and use. And even though I tried them it was just not [for] me" Melanie (Table 3 and 4). The "Americanisation" of the program (i.e. American accent of the virtual coach and characters) was perceived to be a negative aspect by some, and most believed that they would have liked the program more if it were presented by people with local Australian accents. The character examples, where two or three people appeared onscreen to speak about their own experiences using the techniques, were described as "annoying", in that they felt "fake" and "scripted" and broke the momentum of the program for some participants. Some participants found the program to be slow paced and time-consuming, and many would have liked an option to skip ahead at points where they felt they had already grasped the concept and were ready to move on.

The fifth and final theme was: "support from clinician desirable". Although participants valued the anonymity and convenience of the online PCST program, they expressed some desire for some kind of follow-up from a clinician either via email or telephone to "touch 
base" and see how they are progressing, and to reinforce key PCST principles. Participants also believed that the PCST program worked in "tandem" with the home exercise program prescribed by the physiotherapists via Skype ${ }^{\mathrm{TM}}$ in the trial, and that the program would not have been so effective in isolation: "it was like a whole package and I really thought that was really good. If I would have had the physio and then the [online PCST program] or the other way round I don't think it would have worked so well....it's like a tandem thing, like a thing that works together" Sandra (Table 3 and 4). For referral to the PCST program in the future, participants believed that it would be most acceptable and trustworthy for referral to come from a health professional, such as their general practitioner, rather than the program being generically available on the internet or social media (e.g. Facebook).

\section{Discussion}

The aim of this study was to explore the perceptions and experiences of people with OA who completed an online PCST program. We found that participants generally described positive experiences using the program, valuing its anonymity and flexibility and believing that it helped them better manage their pain. However, at times, some participants found that the program was difficult to engage with or relate to, and that it could be time-consuming and slow-paced. Collectively, findings suggest that an online PCST is a broadly acceptable and accessible way in which people with OA can manage their pain, particularly if the program can maintain user engagement and involves support from a clinician.

One perceived advantage of the PCST program was the anonymity and flexibility that it offered participants by being online, rather than delivered in-person by a clinician. This reflects the findings of previous studies investigating perceptions of internet-based psychological programs [17-19]. For example, one study used a survey to evaluate preferences for internet-based psychological interventions, compared to face-to-face, for use of mental health treatment [17]. Participants in that study believed that the main advantages of internet-based interventions were flexibility, accessibility, and anonymity. Another qualitative study explored the perceptions of nine people with bulimia nervosa or related eating disorders who used an internet-based cognitive behavioural program [18]. Those participants found that the program was easy to fit into their lives and they valued the privacy and confidentiality of online delivery. Collectively, these findings suggest that the convenience and accessibility of online delivery has the potential to address barriers to 
cognitive behavioural interventions, such as lack of access to trained therapists as well as the inconvenience of travelling to attend a clinic in-person at a set time [26, 27]. In addition, the self-directed nature and anonymity of online PCST programs may help patients feel more comfortable addressing their pain than if they were to speak to a clinician in-person [28], which may also help people feel more empowered and in control of their condition [17].

Although participants valued the anonymity and privacy of the PCST program, most also believed that having support from a clinician was important, and that it would not have been as effective if not done in conjunction with the physiotherapist-prescribed exercise program. To our knowledge, no previous studies have explored the perceptions of participants who completed an online PCST program (or similar) in addition to receiving care from a clinician. However, previous research does suggest that people who complete online psychological programs also desire some kind of follow-up support from a clinician [17-19]. For example, interviews with people with bulimia nervosa who used an online cognitive behavioural program revealed that receiving email support from clinicians during the intervention was vital to help participants feel more supported and make the experience more personal, as well as provide motivation to complete sessions [18]. Similarly, patients with cancer pain who completed the same online PCST program as in our study [19], required phone calls by study staff to encourage completion of the program. These findings suggest that, although online PCST programs have the potential to be a low cost and accessible way in which people can manage their pain, including some kind of support from a clinician may help improve adherence to, and the effectiveness of, such care [29]. Further research is required to determine how best to combine online self-directed programs with clinician support without compromising the potential cost-effectiveness and convenience of online delivery [30].

Participants in our study believed that, to improve the credibility of the PCST program, it should be recommended to patients by a clinician, rather than being freely available on the internet or advertised on social media. The qualitative study by Rini and colleagues [19] involved focus group interviews with physicians or advanced practice providers who had experience providing care for people with cancer pain. Those clinicians believed that online PCST would be useful, however thought they would have difficulty finding time or remembering to discuss such a program with their patients. They recommended that nurses or pharmacists might be better able to support use of the program because they would have more time to address symptom management and to check patients' progress over time. In 
addition to time pressures, clinicians such as physiotherapists and general practitioners tend to adopt "biomedical" approaches to care (i.e. focus on biological aspects of pain or injury) and are not traditionally trained to provide psychologically informed care to their patients $[31,32]$, and they may not acknowledge, or be aware of, the benefits of doing so. Further investigation is required to determine the best way of directing people with chronic pain to online PCST programs, and whether clinicians believe that they are best-placed to do so.

At times, participants experienced difficulty relating to, and/or engaging with, aspects of the online PCST program. Some participants found that some techniques were not useful for them, and the program was described as often being slow paced. Many believed that they would have liked to have been allowed to skip certain modules that they perceived to be ineffective. Participants with bulimia nervosa also found that some of the content of their online cognitive behavioural therapy program was irrelevant and became repetitive at times [18]. However, those participants also acknowledged that including a range of techniques in the program was important to make it applicable to a broad spectrum of people, and also allowed participants to gain a general understanding of all concepts involved. Similarly, in our study, different participants found different techniques to be useful, suggesting that providing patients with a range of different techniques to try is important. Whether the number of modules can be reduced, or some could be made optional rather than mandatory, without making disengaging participants and sacrificing the potential efficacy of the program is worth consideration.

Our study was conducted in Australia and participants disliked the fact that the program was delivered by people with American accents. This is consistent with evidence that people can have more negative perceptions of people who speak with non-native accents, and believe they are less pleasant to listen to $[33,34]$. These perceptions are likely linked to local culture and a sense of familiarity or similarity, which may influence the perceived trustworthiness and likability of the speaker [35]. Similarly, participants in our study overwhelmingly disliked the character examples presented throughout the program, believing that they "weren't real people" and were difficult to identify with or relate to. People with persistent cancer pain who completed the same online PCST program similarly believed that it should include cancer-relevant examples and depictions of younger people like themselves [19]. Collectively, these findings suggest that online PCST programs will be more acceptable to 
users if they are context-specific and relevant to the local culture and/or the particular patient group.

Our study had a number of strengths and weaknesses. A strength of our study is that we interviewed a range of participants, including males and females of varying ages and occupational status who lived in metropolitan and regional areas across Australia. Our study also had some limitations. Only one researcher (BJL) performed coding and initial organising of data into themes, thus findings may be influenced by her individual beliefs or perceptions. Participants volunteered to participate in the trial and an interview, and as such our data may be biased towards those who have a greater interest in online interventions and who are willing to share their thoughts and experiences. In addition, more than $75 \%$ of our sample had at least some tertiary education, and thus our data may not be generalisable to those with a lower level of education. In fact, there is some evidence that level of education moderates the effects of PCST in people with hip and knee OA, with those who have a higher level of education experiencing greater improvements in outcomes, including pain, fatigue, selfefficacy, and quality of life [36].

In summary, people with knee OA had generally positive experiences using an online PCST program, suggesting that an online PCST is a broadly acceptable and accessible way to help people with $\mathrm{OA}$ to manage their pain. User engagement may be enhanced by redesigning some aspects of the program, such as making some aspects optional and ensuring the program is delivered in a context-specific way that is relevant to the local culture or patient group. A revised version of the PCST program used in this study is now freely available (www.paintrainer.org). In addition, provision of support from a clinician was highlighted as being important, and that the program worked effectively in tandem with the physiotherapistprescribed exercise program. Findings add to existing evidence [12] suggesting that physiotherapists and other clinicians should consider incorporating online PCST programs as an adjunct to recommended core management approaches like exercise.

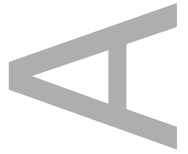

\section{References}

1. Pereira, D., Peleteiro, B., Araujo, J., Branco, J., Santos, R., and Ramos, E., The effect of osteoarthritis definition on prevalence and incidence estimates: a systematic review. Osteoarthritis and Cartilage, 2011. 19(11): p. 1270-1285. 
2. Ackerman, I.N., Bohenseky, M.A., Pratt, C., Gorelik, A., and Liew, D., Counting the cost: The current and future burden of arthritis. 2016, Arthritis Australia.

3. National Institute for Health and Care Excellence, Osteoarthritis - Care and management, clinical guideline CG177, National Institute for Health and Care Excellence, Editor. 2014: London.

4. The Royal Australian College of General Practitioners, Guideline for the management of knee and hip osteoarthritis. 2018, RACGP: East Melbourne, VIC.

5. Woolf, A.D. and Pfleger, B., Burden of major musculoskeletal conditions. Bulletin of the World Health Organization, 2003. 81: p. 646-656.

6. $\quad$ Edwards, R.R., Bingham, C.O., Bathon, J., and Haythornthwaite, J.A., Catastrophizing and pain in arthritis, fibromyalgia, and other rheumatic diseases. Arthritis Care \& Research, 2006. 55(2): p. 325-332.

7. Somers, T.J., Keefe, F.J., Pells, J.J., Dixon, K.E., Waters, S.J., Riordan, P.A., Blumenthal, J.A., McKee, D.C., LaCaille, L., and Tucker, J.M., Pain catastrophizing and pain-related fear in osteoarthritis patients: relationships to pain and disability. Journal of Pain and Symptom Management, 2009. 37(5): p. 863-872.

8. Bhatt, N.G., Sheth, M.S., and Vyas, N.J., Correlation of fear avoidance beliefs with pain and physical function in subjects with osteoarthritis of the knee (OA knee). International Journal of Therapy and Rehabilitation Research, 2015. 4: p. 117-21.

9. Zhang, L., Fu, T., Zhang, Q., Yin, R., Zhu, L., He, Y., Fu, W., and Shen, B., Effects of psychological interventions for patients with osteoarthritis: a systematic review and meta-analysis. Psychology, Health \& Medicine, 2018. 23(1): p. 1-17.

10. Allen, K.D., Choong, P.F., Davis, A.M., Dowsey, M.M., Dziedzic, K.S., Emery, C., Hunter, D.J., Losina, E., Page, A.E., and Roos, E.M., Osteoarthritis: models for appropriate care across the disease continuum. Best practice \& research Clinical rheumatology, 2016. 30(3): p. 503-535.

11. Keefe, F.J. and Somers, T.J., Psychological approaches to understanding and treating arthritis pain. Nature Reviews Rheumatology, 2010. 6(4): p. 210.

12. Bennell, K.L., Ahamed, Y., Jull, G., Bryant, C., Hunt, M.A., Forbes, A.B., Kasza, J., Akram, M., Metcalf, B., and Harris, A., Physical therapist-delivered pain coping skills training and exercise for knee osteoarthritis: randomized controlled trial. Arthritis Care \& Research, 2016. 68(5): p. 590-602.

13. Australian Institute of Health and Welfare. Mental health services in Australia. 2019 [cited 201929 April]; Available from: https://www.aihw.gov.au/reports/mental- 
health-services/mental-health-services-in-australia/report-contents/mental-healthworkforce/psychologist-workforce.

14. Rini, C., Porter, L.S., Somers, T.J., McKee, D.C., and Keefe, F.J., Retaining critical therapeutic elements of behavioral interventions translated for delivery via the Internet: recommendations and an example using pain coping skills training. Journal of Medical Internet Research, 2014. 16(12): p. e245.

15. Rini, C., Porter, L.S., Somers, T.J., McKee, D.C., DeVellis, R.F., Smith, M., Winkel, G., Ahern, D.K., Goldman, R., Stiller, J.L., Mariani, C., Patterson, C., Jordan, J.M., Caldwell, D.S., and Keefe, F.J., Automated Internet-based pain coping skills training to manage osteoarthritis pain: a randomized controlled trial. Pain, 2015. 156(5): p. $837-48$.

16. Bennell, K.L., Nelligan, R.K., Rini, C., Keefe, F.J., Kasza, J., French, S., Forbes, A., Dobson, F., Abbott, J.H., and Dalwood, A., Effects of internet-based pain coping skills training before home exercise for individuals with hip osteoarthritis (HOPE trial): a randomised controlled trial. Pain, 2018. 159(9): p. 1833-1842.

17. Wallin, E.E.K., Mattsson, S., and Olsson, E.M.G., The preference for internet-based psychological interventions by individuals without past or current use of mental health treatment delivered online: a survey study with mixed-methods analysis. JMIR Mental Health, 2016. 3(2): p. e25.

18. Sánchez-Ortiz, V., House, J., Munro, C., Treasure, J., Startup, H., Williams, C., and Schmidt, U., “A computer isn't gonna judge you”: A qualitative study of users' views of an internet-based cognitive behavioural guided self-care treatment package for bulimia nervosa and related disorders. Eating and Weight Disorders-Studies on Anorexia, Bulimia and Obesity, 2011. 16(2): p. e93-e101.

19. Rini, C., Vu, M.B., Lerner, H., Bloom, C., Carda-Auten, J., Wood, W.A., Basch, E.M., Voorhees, P.M., Reeder-Hayes, K.E., and Keefe, F.J., A qualitative study of patient and provider perspectives on using web-based pain coping skills training to treat persistent cancer pain. Palliative \& Supportive Care, 2018. 16(2): p. 155-169.

20. Nguyen, U.-S.D., Zhang, Y., Zhu, Y., Niu, J., Zhang, B., and Felson, D.T., Increasing prevalence of knee pain and symptomatic knee osteoarthritis: survey and cohort data. Annals of Internal Medicine, 2011. 155(11): p. 725-732.

21. Bennell, K.L., Nelligan, R., Dobson, F., Rini, C., Keefe, F., Kasza, J., French, S., Bryant, C., Dalwood, A., and Abbott, J.H., Effectiveness of an internet-delivered 
exercise and pain-coping skills training intervention for persons with chronic knee pain: A randomised trial. Annals of Internal Medicine, 2017. 166(7): p. 453-462.

22. Tong, A., Sainsbury, P., and Craig, J., Consolidated criteria for reporting qualitative research (COREQ): a 32-item checklist for interviews and focus groups. International Journal for Quality in Health Care, 2007. 19(6): p. 349-57.

23. Dobson, F.L., Hinman, R.S., French, S., Rini, C., Keefe, F., Nelligan, R., Abbott, J.H., Bryant, C., Staples, M.P., Dalwood, A., and Bennell, K.L., Internet-mediated physiotherapy and pain coping skills for knee pain (IMPACT-knee pain): randomised controlled trial protocol. BMC Musculoskeletal Disorders, 2014. 15(279): p. doi: 10.1186/1471-2474-15-279.

24. Bowen, G.A., Naturalistic inquiry and the saturation concept: a research note. Qualitative Research, 2008. 8(1): p. 137-152.

25. Morse, J.M. and Field, P.A., Qualitative research methods for health professionals. 2nd ed. 1995, Thousand Oaks, CA.: Sage Publications.

26. Gunter, R.W. and Whittal, M.L., Dissemination of cognitive-behavioral treatments for anxiety disorders: Overcoming barriers and improving patient access. Clinical Psychology Review, 2010. 30(2): p. 194-202.

27. Shafran, R., Clark, D., Fairburn, C., Arntz, A., Barlow, D., Ehlers, A., Freeston, M., Garety, P., Hollon, S., and Ost, L., Mind the gap: Improving the dissemination of CBT. Behaviour Research and Therapy, 2009. 47(11): p. 902-909.

28. Heckemann, B., Wolf, A., Ali, L., Sonntag, S.M., and Ekman, I., Discovering untapped relationship potential with patients in telehealth: a qualitative interview study. BMJ Open, 2016. 6(3): p. e009750.

29. Gerhards, S., Abma, T., Arntz, A., De Graaf, L., Evers, S., Huibers, M., and Widdershoven, G., Improving adherence and effectiveness of computerised cognitive behavioural therapy without support for depression: a qualitative study on patient experiences. Journal of Affective Disorders, 2011. 129(1-3): p. 117-125.

30. Wentzel, J., van der Vaart, R., Bohlmeijer, E.T., and van Gemert-Pijnen, J.E., Mixing online and face-to-face therapy: how to benefit from blended care in mental health care. JMIR Mental Health, 2016. 3(1): p. e9.

31. Foster, N.E. and Delitto, A., Embedding psychosocial perspectives within clinical management of low back pain: integration of psychosocially informed management principles into physical therapist practice-challenges and opportunities. Physical Therapy, 2011.91(5): p. 790-803. 
32. Alexanders, J., Anderson, A., and Henderson, S., Musculoskeletal physiotherapists' use of psychological interventions: a systematic review of therapists' perceptions and practice. Physiotherapy, 2015. 101(2): p. 95-102.

33. Gluszek, A. and Dovidio, J.F., The way they speak: a social psychological perspective on the stigma of nonnative accents in communication. Personality and Social Psychology Review, 2010. 14(2): p. 214-37.

34. Tamagawa, R., Watson, C.I., Kuo, I.H., MacDonald, B.A., and Broadbent, E., The effects of synthesized voice accents on user perceptions of robots. International Journal of Social Robotics, 2011. 3(3): p. 253-262.

35. Nass, C. and Brave, S., Wired for Speech: How Voice Activates and Advances the Human-Computer Relationship. 2005, Cambridge, MA: The MIT Press.

36. Broderick, J.E., Keefe, F.J., Schneider, S., Junghaenel, D.U., Bruckenthal, P., Schwartz, J.E., Kaell, A.T., Caldwell, D.S., McKee, D., and Gould, E., Cognitive behavioral therapy for chronic pain is effective, but for whom? Pain, 2016. 157(9): p. 2115-2123.

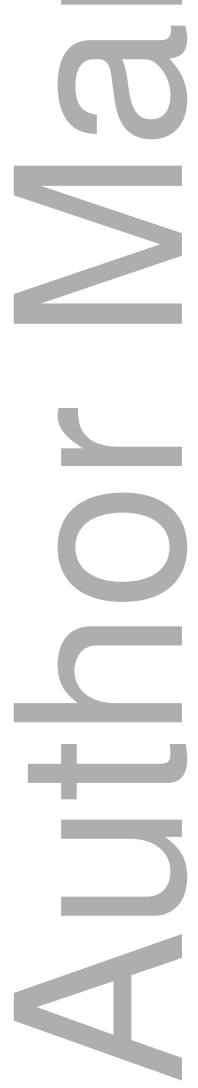


Table 1. Summary of the online pain coping skills training program content

\begin{tabular}{|c|c|c|}
\hline & $\begin{array}{l}\text { Name of } \\
\text { technique/skill }\end{array}$ & Content of module \\
\hline 1 & $\begin{array}{l}\text { Progres } \\
\text { relaxati }\end{array}$ & $\begin{array}{ll}\text { - } & \text { Introduce program and concept of pain coping skills } \\
\text { - } & \text { Teach gate control theory } \\
\text { - } & \text { Introduce progressive muscle relaxation and lead practice session } \\
\text { - } & \text { Evaluate feelings of relaxation after practice } \\
\text { - } & \text { Identify strategies to overcome obstacles to use of skill } \\
\text { - } & \text { Set goal for practice sessions over next week }\end{array}$ \\
\hline 2 & $\begin{array}{l}\text { ces (brief } \\
\text { kills) }\end{array}$ & $\begin{array}{ll}\text { - } & \text { Review progressive muscle relaxation and completed practice sessions } \\
\text { - } & \text { Introduce "mini-practices" and lead practice session } \\
\text { - } & \text { Evaluate pain after practice } \\
\text { - } & \text { Identify strategies to overcome obstacles to use of skill } \\
\text { - } & \text { Set goal for practice sessions over next week }\end{array}$ \\
\hline 3 & t cycling & $\begin{array}{ll}\text { - } & \text { Review mini-practices and completed practice sessions } \\
\text { - } & \text { Introduce activity/rest cycling and identify activities that participant may } \\
& \text { overdo } \\
\text { - } & \text { Show examples to demonstrate how to change overdone activities } \\
\text { - } & \text { Create plan to incorporate plan into daily routine } \\
\text { - } & \text { Set goal for practice sessions over next week }\end{array}$ \\
\hline 4 & $\begin{array}{l}\text { Pleasant activity } \\
\text { scheduling and } \\
\text { identify negative } \\
\text { automatic thoughts }\end{array}$ & $\begin{array}{ll}\text { - } & \text { Review activity/rest cycling and completed practice sessions } \\
\text { - } & \text { Introduce pleasant activity scheduling and demonstrate example of how to } \\
& \text { select and add pleasant activities to routine } \\
\text { - } & \text { Schedule pleasant activities for week and problem-solve barriers } \\
\text { - } & \text { Introduce negative automatic thoughts and demonstrate how to identify them } \\
\text { - } & \text { Set goal for practice sessions over next week }\end{array}$ \\
\hline 5 & $\begin{array}{l}\text { Identify/change } \\
\text { negative automatic } \\
\text { thoughts and coping } \\
\text { thoughts }\end{array}$ & $\begin{array}{ll}\text { - } & \text { Review pleasant activity scheduling and completed practice sessions } \\
\text { - } & \text { Introduce coping thoughts and lead example creating coping thoughts } \\
\text { - } & \text { Identify strategies to overcome obstacles to use of skill } \\
\text { - } & \text { Set goal for practice sessions over next week }\end{array}$ \\
\hline 6 & $\begin{array}{l}\text { Pleasant imagery and } \\
\text { distraction } \\
\text { techniques }\end{array}$ & $\begin{array}{ll}\text { - } & \text { Review coping thoughts and completed practice sessions } \\
\text { - } & \text { Introduce pleasant imagery and provide opportunity to practice } \\
\text { - } & \text { Set goal for practice sessions over next week }\end{array}$ \\
\hline 7 & Problem Solving & $\begin{array}{ll}\text { - } & \text { Review pleasant imagery and completed practice sessions } \\
\text { - } & \text { Introduce concept of problem solving and demonstrate use of skill } \\
\text { - } & \text { Practice selecting skills for different situations } \\
\text { - } & \text { Set goal for practice sessions over next week }\end{array}$ \\
\hline
\end{tabular}


- Review all sessions

8

- Evaluate skill use, helpfulness, and comparison to other user experiences

- Develop plan for maintenance of skills

- Motivate further practice and skill development

- $\quad$ Review practice goals

Adapted from Rini, Porter [15]
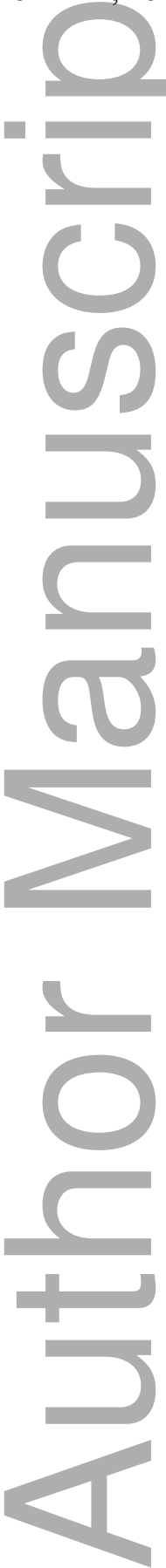


\section{Table 2. Semi-structured interview guide}

1. Think back to when you first started the online PCST program, what were your initial thoughts about the program?

What were your expectations of using the online PCST program for your knee problems at the start of the program?

2. What did you learn from the [online PCST] program?

What did you learn about how thoughts, feelings, or behaviours can affect your pain?

Was this new information for you or was it a "refresher" for knowledge you already had? if

the latter, where did you get this information/knowledge previously?

3. In what ways did or didn't the online PCST program help you become more aware of how your thoughts, feelings or behaviours affect your pain?

What was helpful about the online PCST program?

What about the program did you find less helpful if anything in helping you understand the role of feelings thoughts and behaviours?

4. What is your impression of learning these skills like you did, on the computer without face to face contact from any professional?

What did you like about the program /what didn't you like?

What stands out as different from the skills training in the online PCST program from the way you have learned things face to face with a health professional before?

What do you think is the best way to learn a new skill?

5. What particular pain coping skills stand out as most useful to you in your daily life?

How are you using them? How do they help?

What was least useful?

What else, if anything, would you have liked the program to do that would have addressed any difficulties you had when you were practicing the skills?

6. So what specifically about the online PCST program helped you learn the skills to be able to use them in your daily life?

Thoughts on presenter dialogue/ interactive exercises/ability to reflect or stories told by characters? What did you do if you didn't understand something initially?

7. How did you feel doing the physiotherapy exercise at the same time as the online PCST sessions? What role did the physiotherapist play (if any) in helping you understand the skills and how they could be useful? How did you find the time commitment?

8. Since having had the experience of the online PCST program how have things changed for you (positive or negative) - regarding your knee pain or how you feel physically or emotionally?

How have you changed? What would you say is the most lasting impact of the program?

9. What additional advice do you have for us about the online PCST program and the information it contains as we begin to improve this program to use with people suffering from knee symptoms in the wider Australian community?

Thoughts on length - currently is 8 weeks long. Was that too long, too short, or just about right?

How best to access ie referred to the website by a health professional, just something you find in a google 
search ie on arthritis advocacy websites.

10. Is there anything else you would like to add about your experience with the online PCST program? PCST: pain coping skills training

Questions in italics were used as prompts if necessary.

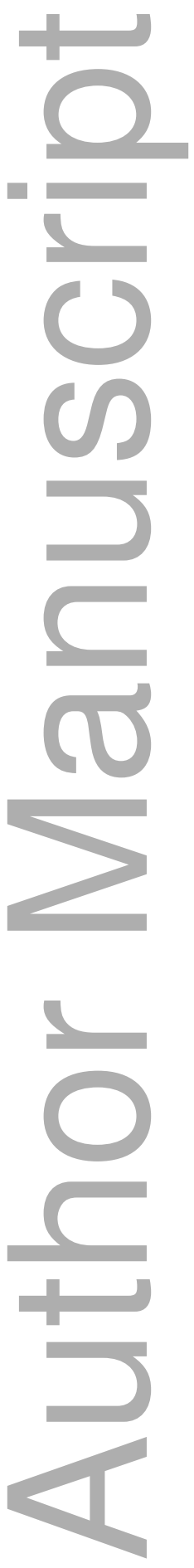


Table 3. Participant details $(n=12)$

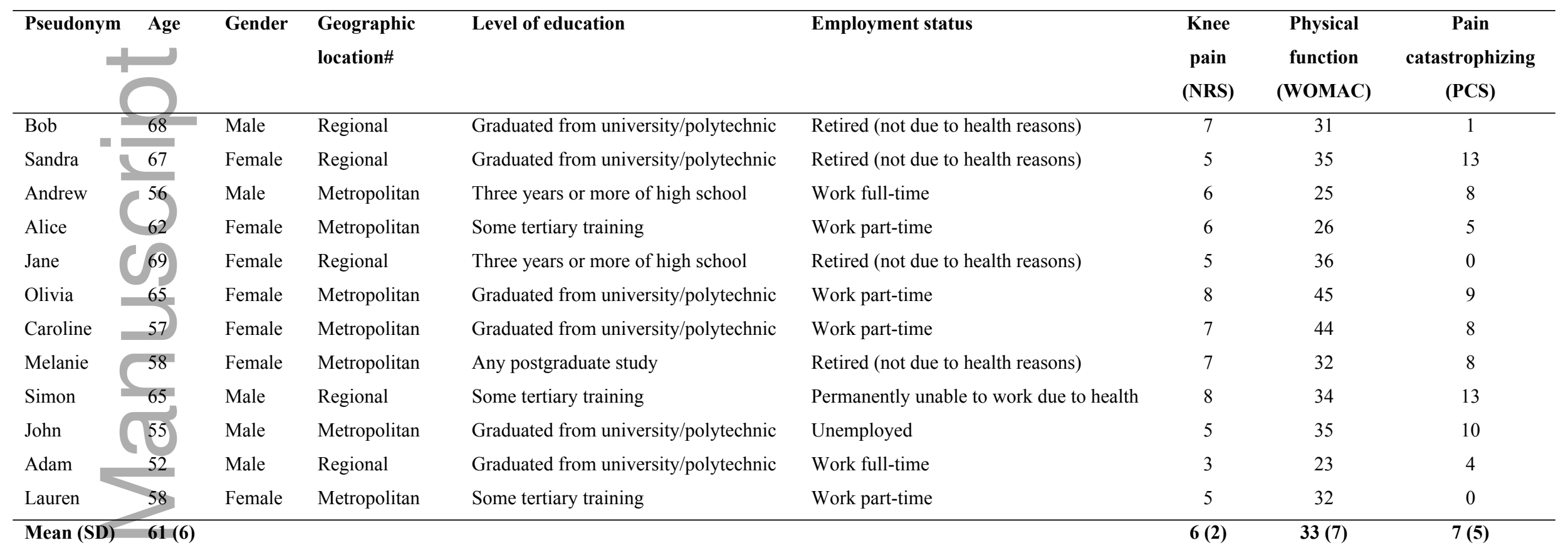

\#Defined according to The Australian Statistical Geography Standard Remoteness Structure (http://www.abs.gov.au/websitedbs/d3310114.nsf/home/remoteness+structure) NRS: numeric rating scale; ranges from 0 to 10 where lower scores indicate less pain

WOMAC: Western Ontario and McMaster Universities Osteoarthritis Index - physical function sub-scale; ranges from 0 to 68 , where lower scores indicate better function

PCS: Pain Catastrophizing Scale; ranges from 0 to 52, higher scores indicate greater catastrophizing

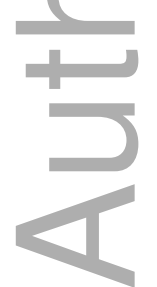

This article is protected by copyright. All rights reserved 
Table 4. Themes, sub-themes, and exemplary quotes

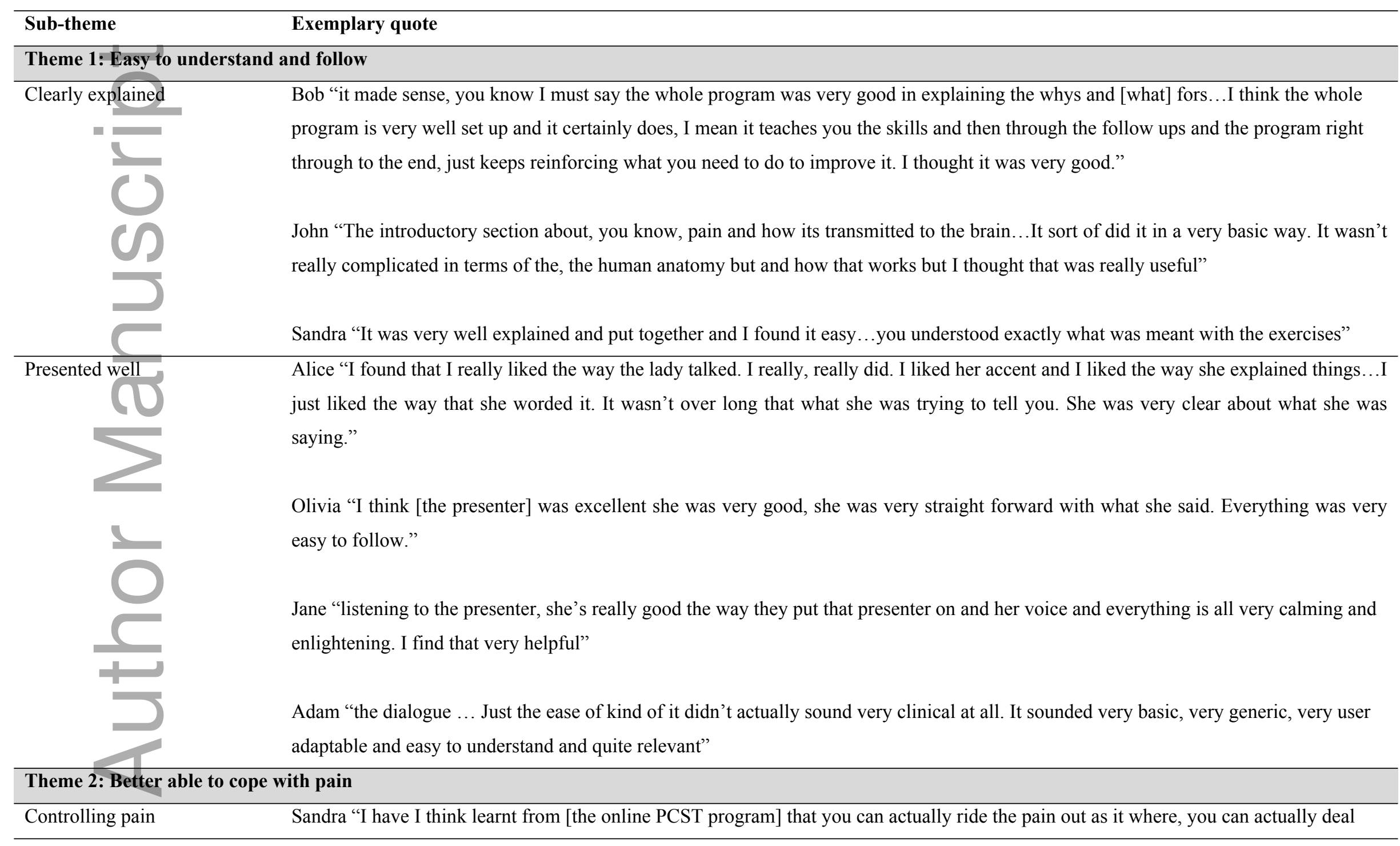

This article is protected by copyright. All rights reserved 


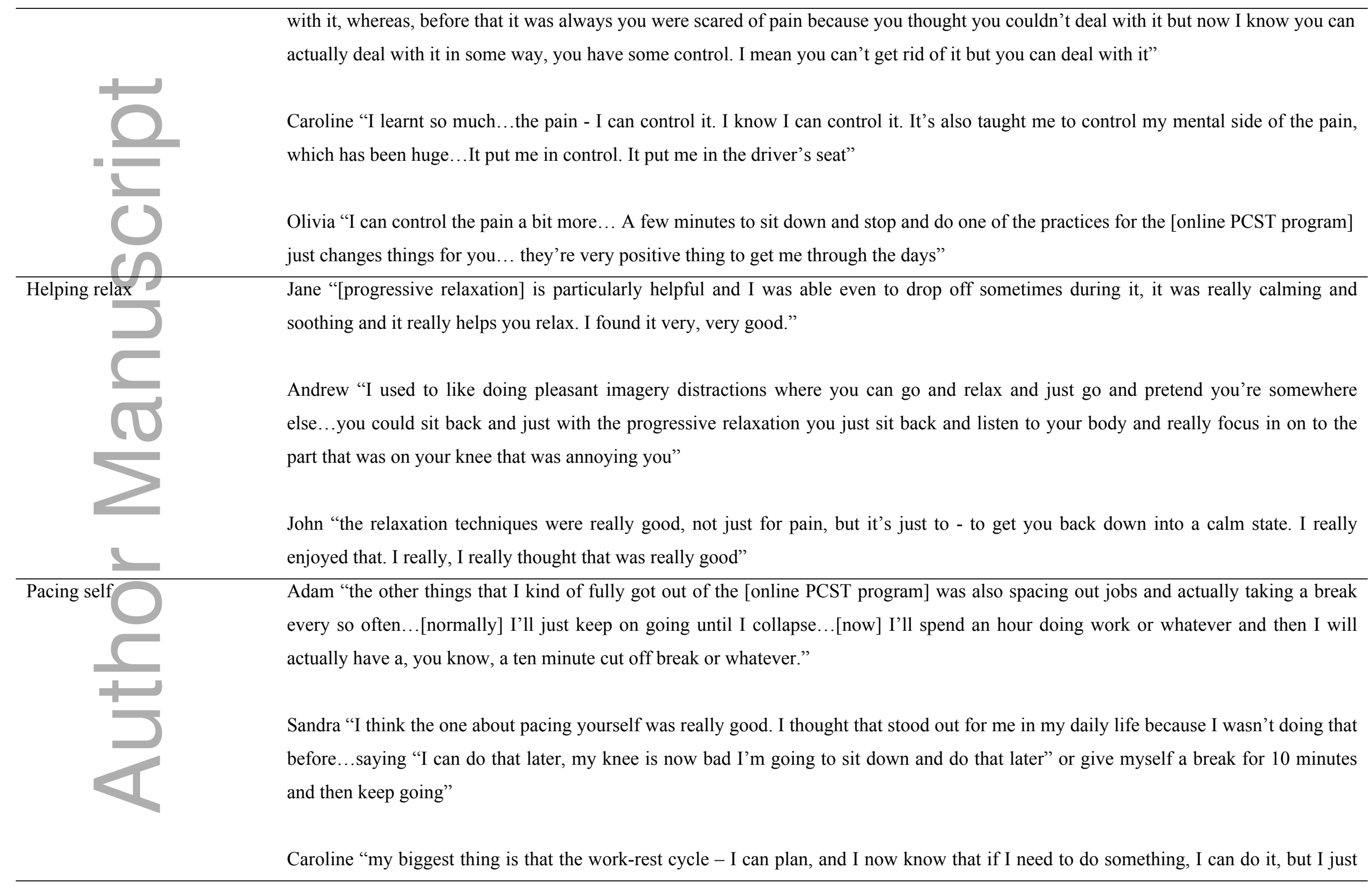

This article is protected by copyright. All rights reserved 
break it down into smaller amounts...I will rest it, and then I'll go back and I'll go back to where I need to be and do things in smaller amounts."

\begin{tabular}{|c|c|}
\hline $\begin{array}{l}\text { Incorporating skills into } \\
\text { exercise program }\end{array}$ & $\begin{array}{l}\text { Bob "if you're doing the exercises, you start to get pain or whatever, you can stop and take a few deep breaths and sort of re-focus before } \\
\text { you get back to it...taking a break, a rest cycle, doing some of the other stuff, the pleasant imagery or whatever to help them get through } \\
\text { the exercise program." } \\
\text { Jane "it was helpful when you're doing the exercises because you might, when you're feeling in pain you can go to your [online PCST } \\
\text { program] and learn how to cope with that and do your relaxation techniques as well to help you if you're feeling any pain from your } \\
\text { exercises or from what you're doing around the house. So it is helpful to have them in conjunction" }\end{array}$ \\
\hline & $\begin{array}{l}\text { Jane "I liked the presenter even though she wasn't there with me...sometimes [a clinician] might be a bit smart, they're very } \\
\text { knowledgeable and they are making out they are so you might be thinking well they're a bit smart sort of thing so you don't feel as } \\
\text { comfortable with them. So it was good on the computer the way that woman presented herself." }\end{array}$ \\
\hline Work at own & $\begin{array}{l}\text { Sandra "It's just something you can go back anytime you want to, you can think "oh, what did they mean with that" and you go back and } \\
\text { you just see it again. If you're talking to someone in an office you can't go back and say "what did you mean by that?", you know what I } \\
\text { mean? It was for me it was perfect" } \\
\text { Jane "on the computer being able to go in there and be able to replay if you wanted to listen to the segment over and over again. I thought } \\
\text { that was very helpful as a lot of us tend to forget very easily and I find it's better, myself, to see it on the computer like that, interact with } \\
\text { it" }\end{array}$ \\
\hline Accessibility & Andrew "you could do it at your time when you had the time... if you didn't feel like doing it today you do it tomorrow or something. If \\
\hline
\end{tabular}

This article is protected by copyright. All rights reserved 
you only want to do half of it you could do half of it and go back another day"

Sandra "I liked the fact that I could do it in my own time when I was ready to do it and when I really needed it. I didn't have to worry about going somewhere having appointments."

Adam "The fact that you can just access it at any point in time. It was online like, you know, there were a few times when I did it while my son was doing soccer training in the evenings and there were a view times like on a Sunday morning when I just sort of log in quietly while I was chilling up in bed and I'd watch it."

Theme 4: Not always relatable or engaging

\begin{tabular}{|c|c|}
\hline Some techniques not useful & $\begin{array}{l}\text { Melanie "if you were able to pull off and say look, I like the look of this technique and that one and so customise the delivery a bit. I think } \\
\text { that probably would have been better for me... you get to a point and you go I can't be bothered. I'm not finding the benefit that it's asking } \\
\text { me to do. Not the [techniques] I felt comfortable with, it asked me to do those other ones and I was thinking "I don't want to do that"; sit } \\
\text { there and think about being on a beach. I don't want to think about that" }\end{array}$ \\
\hline & $\begin{array}{l}\text { Lauren "[the online PCST program] wasn't my cup of tea, so to speak, that's all, and sure, it might help for some people but, you know - } \\
\text { like on some of the tapings on there, you know, I'm sure maybe it helped some people but I don't know, I didn't find it all that beneficial" }\end{array}$ \\
\hline & $\begin{array}{l}\text { John "the pleasant activity scheduling and all that sort of stuff, you've really got to try and, you know, program something in your life, get } \\
\text { some spare time in your life to do all of that. So that's a little more difficult to do and as I said before I didn't really think that that added } \\
\text { much value to me personally" }\end{array}$ \\
\hline $\begin{array}{l}\text { Americanisation of the } \\
\text { program }\end{array}$ & Andrew "the only thing I didn't like the American accent... get rid of those American accents" \\
\hline & $\begin{array}{l}\text { Olivia "I don't particularly like the Americanisation it was very American...it would be a problem for some people I think... it would be } \\
\text { better with a program more based in Australia" }\end{array}$ \\
\hline
\end{tabular}

This article is protected by copyright. All rights reserved 


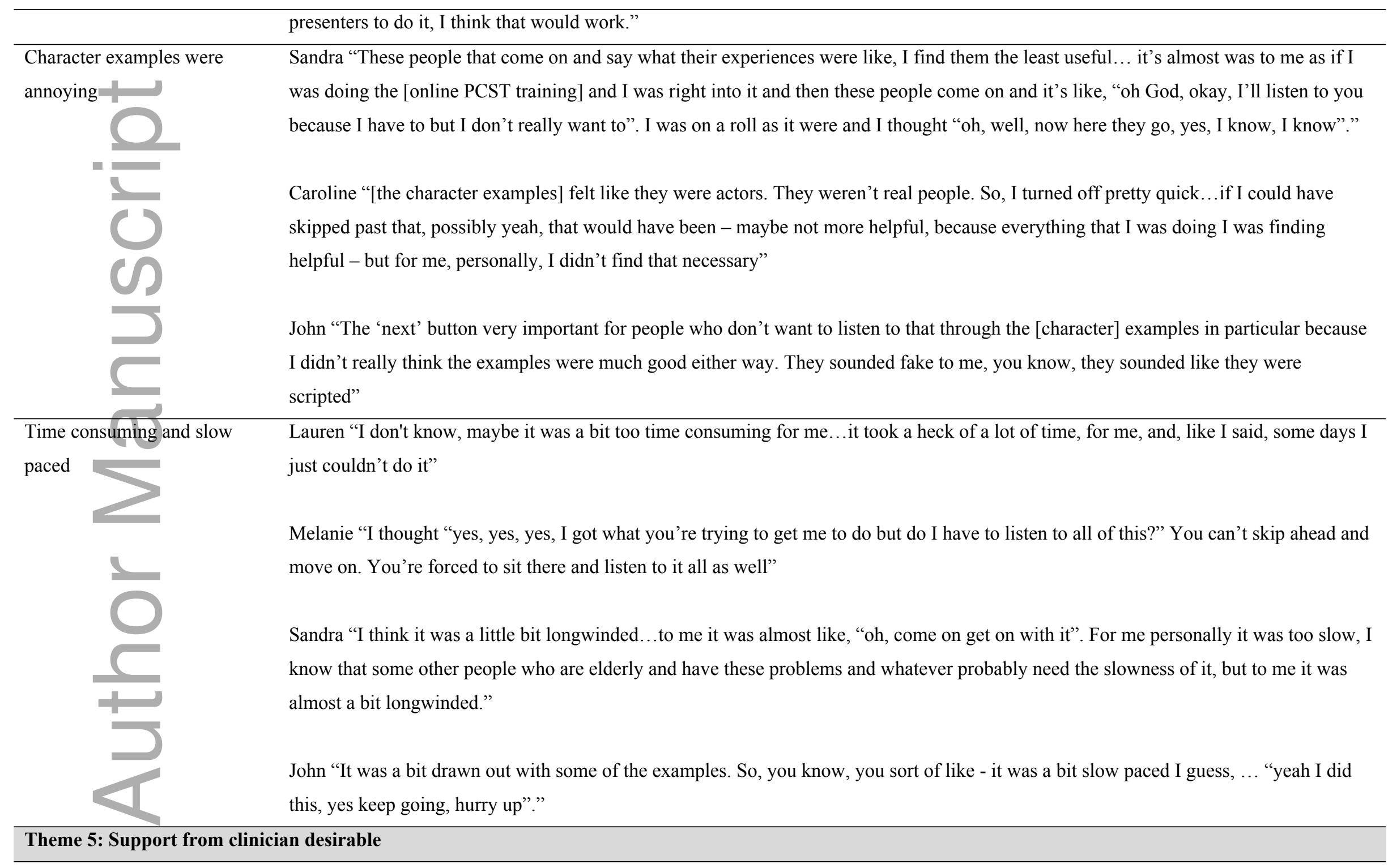

This article is protected by copyright. All rights reserved 


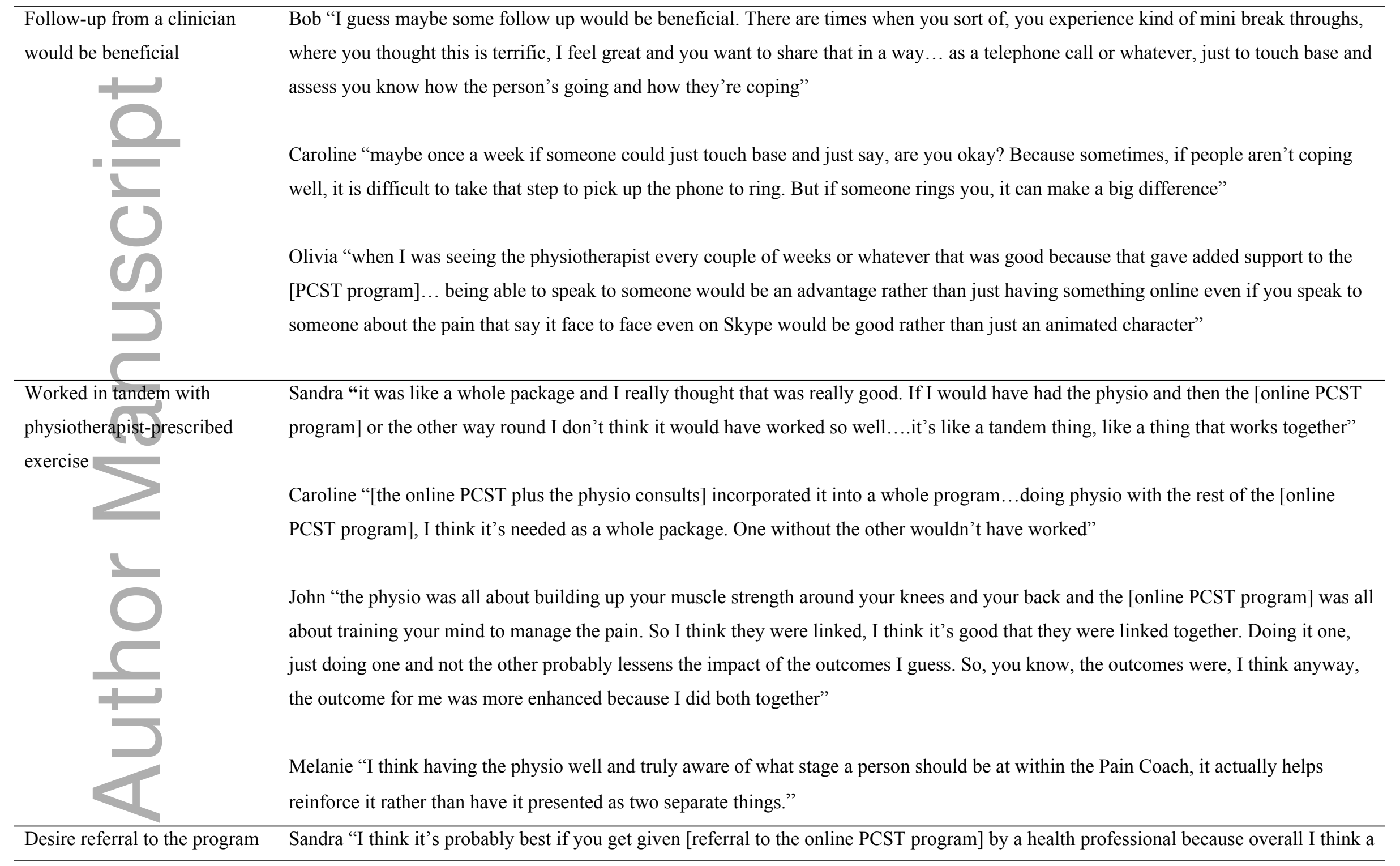

This article is protected by copyright. All rights reserved 
by trusted source

lot of people don't use computers very much in that sense, they don't go and Google it... the doctor can say "look, there is this program" and I'm sure people would access it."

Olivia "if a health professional referred you there maybe you're more inclined to take notice of it. Then an arthritis website you're more inclined to take notice of it."

John "if a health professional told me to do something, I know that the health professional is saying you need to do this because its going be beneficial to you. So I think you get more impact from a health professional telling you to do that or suggesting that as part of your treatment" 


\section{University Library}

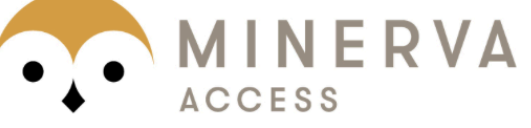

A gateway to Melbourne's research publications

Minerva Access is the Institutional Repository of The University of Melbourne

Author/s:

Lawford, BJ;Hinman, RS;Nelligan, RK;Keefe, F;Rini, C;Bennell, KL

Title:

"I Could Do It in My Own Time and When I Really Needed It": Perceptions of Online Pain Coping Skills Training For People With Knee Osteoarthritis

Date:

2020-12-01

Citation:

Lawford, B. J., Hinman, R. S., Nelligan, R. K., Keefe, F., Rini, C. \& Bennell, K. L. (2020). "I Could Do It in My Own Time and When I Really Needed It": Perceptions of Online Pain Coping Skills Training For People With Knee Osteoarthritis. ARTHRITIS CARE \& RESEARCH, 72 (12), pp.1736-1746. https://doi.org/10.1002/acr.24093.

Persistent Link:

http://hdl.handle.net/11343/276657 